\title{
Root Canal Treatment of Mandibular First Molar with Radix Entomolaris
}

\author{
Ratna Meidyawati, Endang Suprastiwi \\ Departemen of Conservative Dentistry, Faculty of Dentistry, Universitas Indonesia, Jakarta, Indonesia \\ Email: esuprastiwi@yahoo.co.id
}

How to cite this paper: Meidyawati, R. and Suprastiwi, E. (2016) Root Canal Treatment of Mandibular First Molar with Radix Entomolaris. Open Journal of Stomatology, 6, 193-200.

http://dx.doi.org/10.4236/ojst.2016.69025

Received: August 21, 2016

Accepted: September 25, 2016

Published: September 28, 2016

Copyright $\odot 2016$ by authors and Scientific Research Publishing Inc. This work is licensed under the Creative Commons Attribution International License (CC BY 4.0).

http://creativecommons.org/licenses/by/4.0/

\begin{abstract}
Aim: To confirm the effect of root canal treatment on radix entomolaris. Case: Radix entomolaris was an additional root that located on the distolingual of mandibular first molars. In this case, the radix entomolaris was detected clinically and radiographically with root canal configuration such as curves. An awareness and understanding of this unusual root and root canal morphology could contribute to the successful outcome of endodontic treatment. Conclusion: Root canal treatment on this case shows the lack of symptoms and normal radiographic presentation for two months follow-up.
\end{abstract}

\section{Keywords}

Root Canal Treatment, Radix Entomolaris, Root Anatomy, Mandibular First Molar

\section{Introduction}

An awareness and understanding presence of unusual root canal morphology could contribute to successful outcome of endodontic treatment [1]-[9]. Mandibular first molar could have several variations of root anatomy and usually has two mesial roots and one distal. The distal root typically has one kidney-shaped root canal, and if the orifice is particularly narrow and round, a second distal canal may be present [10]. Moreover, the presence of three mesial canals and three distal canals had also been reported in the mandibular first molar. An additional third root, first mentioned in the literature by Carabelli (1844), was called the radix entomolaris by Bolk (1915). This supernumerary root was located in the distolingual of mandibular molars, mainly the first molars [1]-[12]. The clinical approach to diagnosis and endodontic treatment on mandibular first molar with radix entomolaris will be discussed and illustrated in this case report.

\section{Case Report}

A 39-year-old female patient was referred for endodontic treatment of the mandibular 
left first molar. The patient chief complaint was pain while chewing in the lower left back tooth region. Clinical examination shows exposal of the pulp chamber (Figure $1(a)$ ) and the tooth was sensitive on percussion test. The radiographic examination showed curved canals and signs of apical periodontitis on mesial and distal roots. A further inspection of the preoperative radiograph shows two outline of the distal root contour and an unclear view of the distal root canal (Figure 1(b)), which could indicate the presence of an additional third root.

Upon opening the pulp chamber, the outline form was found more trapezoidal in shape than triangular, with two mesial and two distal canal orifices. The root canals were explored with a \# $10 \mathrm{~K}$-file (Dentsply, Maillefer USA) and the working length of these canals were determined electronically using an apex locator (Raypex 6, VDW Germany) and then confirmed with radiograph. From the unusual location of the orifice which away from distolingual (Figure 2(a)) and while determining working length from radiograph (Figure $2(\mathrm{~b})$ ), the presence of the radix entomolaris was confirmed. The working length of mesiobuccal was $20 \mathrm{~mm}$, mesiolingual $20,5 \mathrm{~mm}$, distobuccal 18 $\mathrm{mm}$, and distolingual $20 \mathrm{~mm}$.

An artificial wall was made with composite resin (Filtek Z 350 XT, 3M ESPE). Glide path was done using K-file (Dentsply, Maillefer USA) to size \# 15 root canals were prepared using ProTaper Next (Dentsply, Maillefer USA) to size X 2 (Figure 3(a) and Figure 3(b)).

During cleaning and shaping procedure, root canals were irrigated with a combination of $2.5 \%$ sodium hypochlorite and 17\% EDTA (MD-Cleanser, Meta Biomed). Root canals were dried andfilled calcium hydroxide (Calcipex II, Nishika) as an intracanal medicament.

In the second visit, irrigation performed to remove the calcium hydroxide residues

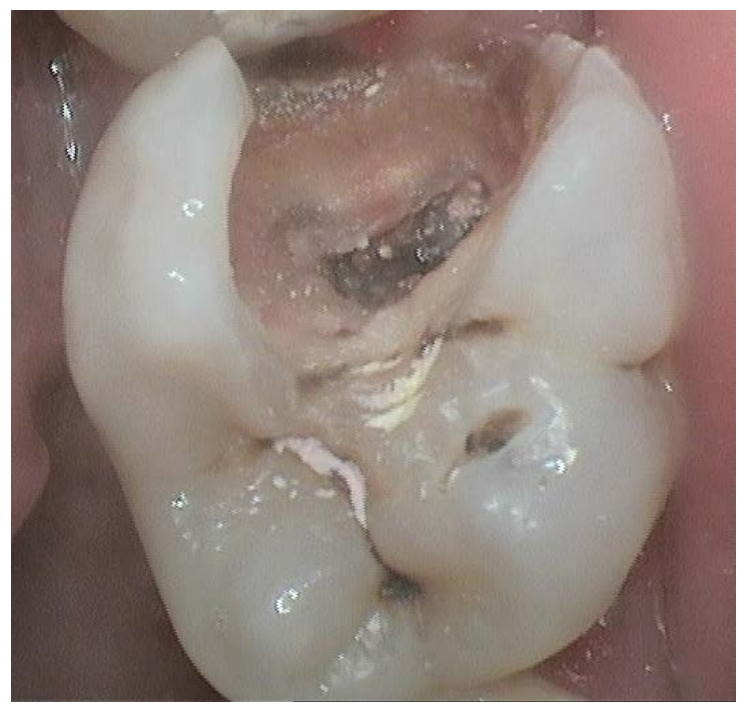

(a)

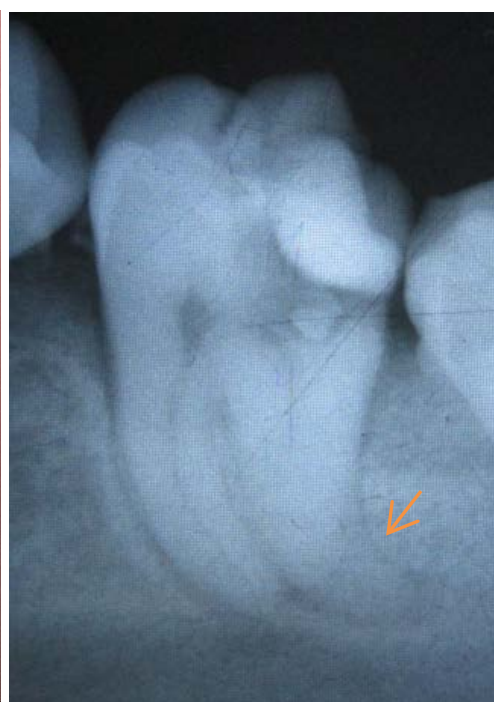

(b)

Figure 1. a) Preoperative clinical images. b) Preoperative radiograph; can be seen two outlines of the distal root contour (arrow). 


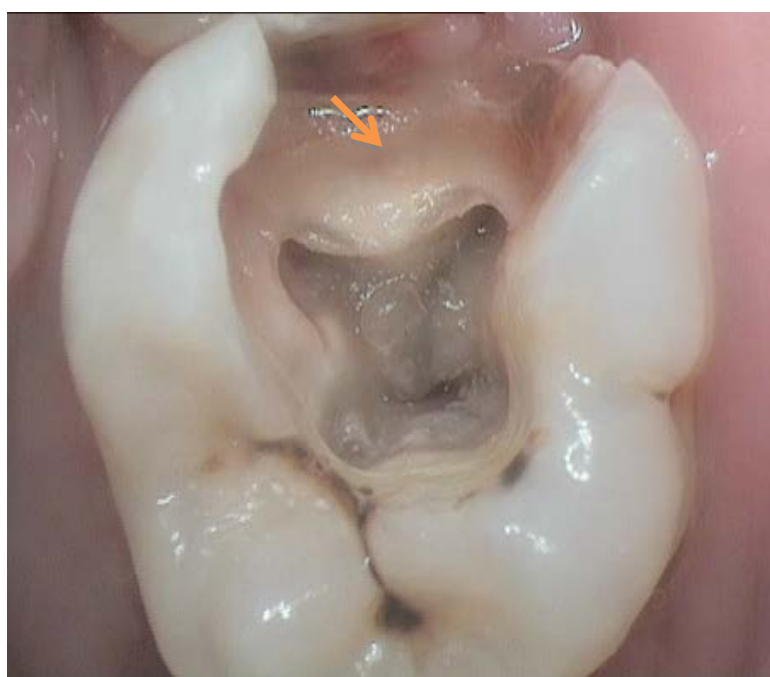

(a)

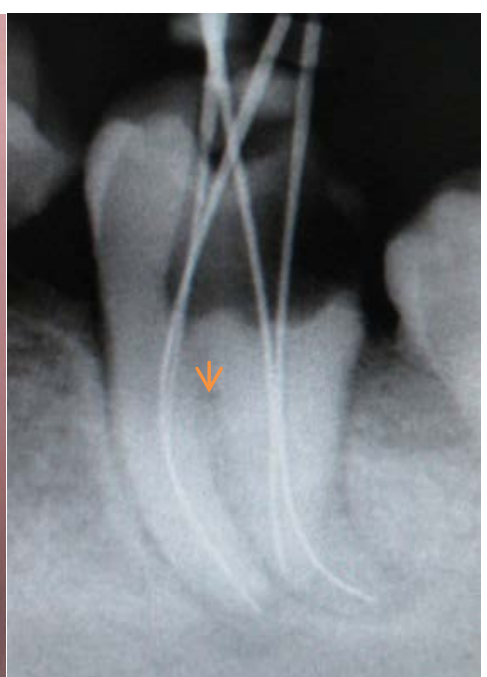

(b)

Figure 2. a) Occlusal view of the pulp chamber floor with the orifice of the radix entomolaris (arrow). b) Working length determination radiograph; can be seen a superimposition of two distal roots (arrow: radix entomolaris).

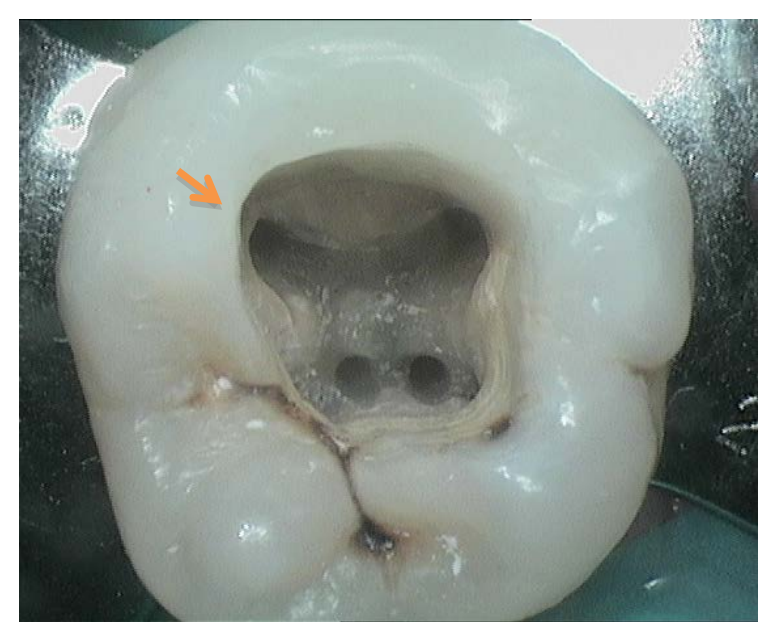

(a)

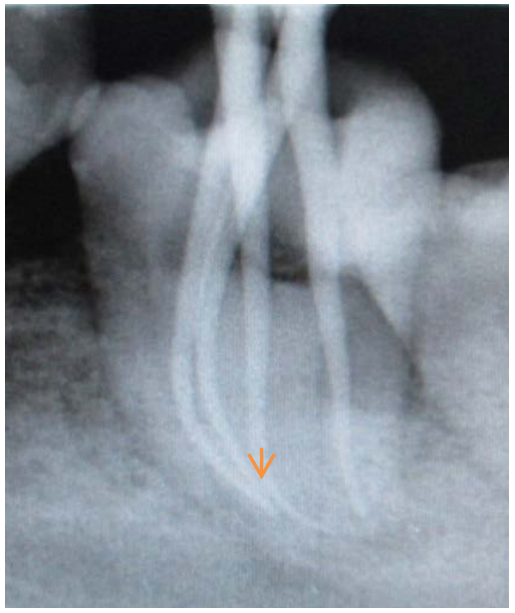

(b)

Figure 3. a) Clinical image after root canal preparation. b) Guttapercha cone fit radiograph (arrow: radix entomolaris).

from root canals. Obturation were done with guttapercha and epoxy resin sealer $(\mathrm{AH}$ Plus, Dentsply, Maillefer USA) and completed using downpack-backfill technique with Elements (SybronEndo) (Figure 4(a) and Figure 4(b)).

The tooth was then prepared for the composite onlay in the third visit (Figure 4(c)). Indirect composite onlay was performed in the dental laboratory and cemented with resin cement (Breeze, Pentron Clinical) (Figure 4(d)).

Figure 5 explains the condition of periapical tissue before treatment (a), after filling the root canal (b) and control after 2 months of treatment (c). Peripapical tissue repair occurs with the loss of radiolicency apperance. 


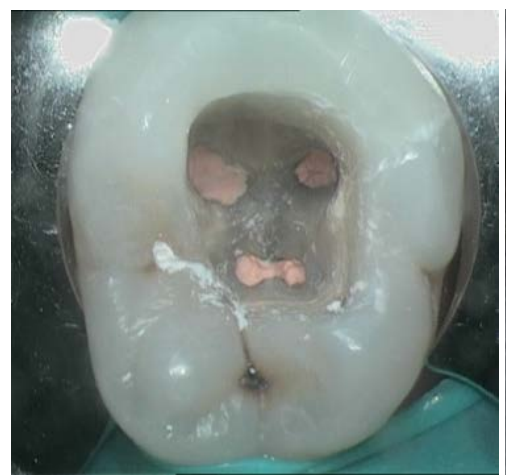

(a)

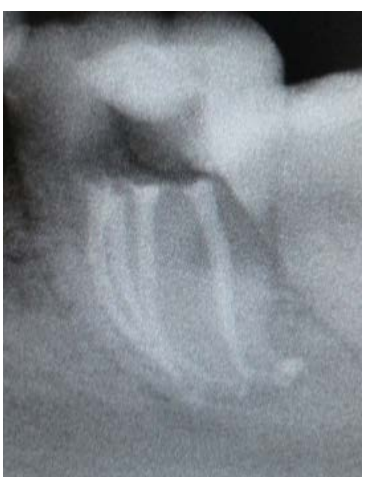

(b)

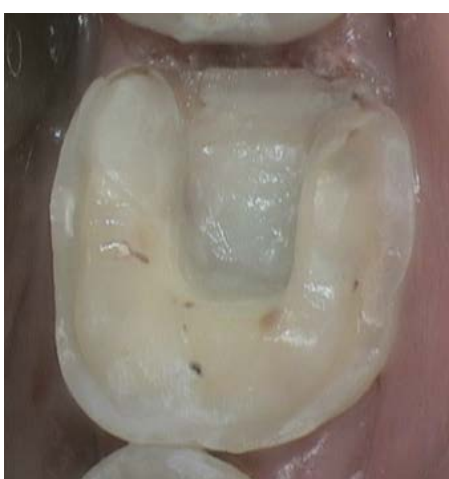

(c)

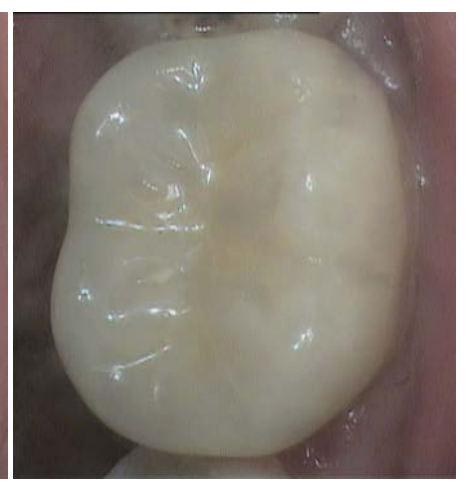

(d)

Figure 4. a) Clinical image after root canal obturation. b) Radiograph root canal obturation. c) Occlusal view of the onlaycavity. d) Clinical image after composite onlay cementation.

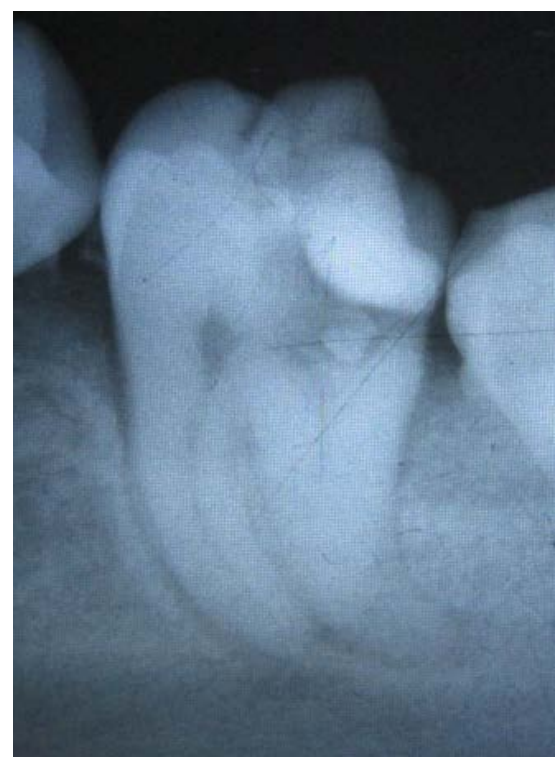

(a)

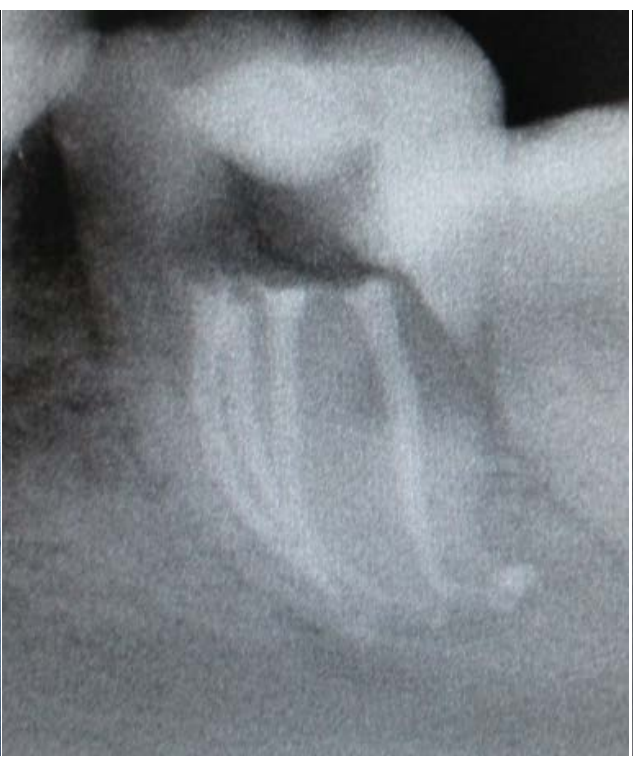

(b)

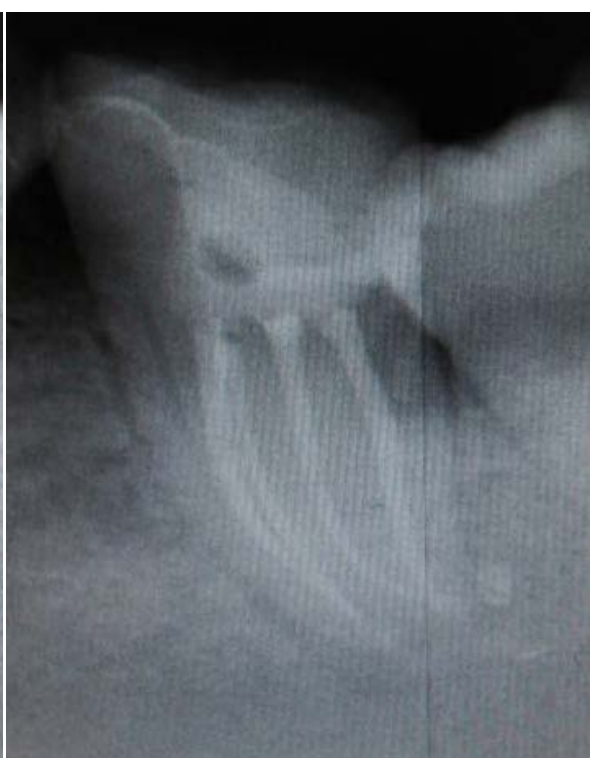

(c)

Figure 5. a) Preoperative radiograph. b) Radiograph ofroot canal obturation. c) Radiograph after 2-month obturation.

\section{Discussion}

The prevalence of these three-rooted mandibular first molars appears to be less than $3 \%$ in African populations, do not exceed $4.2 \%$ in Caucasians, less than $5 \%$ in Eurasian and Asian populations, and higher than 5\% (even up to $40 \%$ ) in populations with Mongolian traits. In the presence of radix entomolaris, an extension of the triangular cavity opening to the distolingual results in a more rectangular or trapezoidal outline form with two mesial and two distal canal orifices. The separate radix entomolaris mostly situated in the same bucco-lingual plane as the distobuccal root, so a superimposition of both roots could appear from the radiograph. Second radiograph should be taken especially with SLOB technique (Same-Lingual, Opposite-Buccal) to find the extra root. While determining the working length, radiograph shows superimposition of two distal roots. From the unusual orifice location which was far to the distolingual and con- 
firmed from the radiograph there was an extra root canal, the presence of the radix entomolaris could be confirmed. The dimensions of the radix entomolaris may vary from a short conical extension to a mature root with normal length and root canal [2]-[6] [8]-[12]. In this case, the radix entomolaris showed a mature root with normal length and root canal.

A classification by Carlsen and Alexandersen (1990) describes four different types of radix entomolaris according to the location of the cervical part of the radix entomolaris: types A, B, C, and AC. Type A refer to a distally located cervical part of the radix entomolaris with two normal distal root components. Type B refers to a distally located cervical part of the radix entomolaris with one normal distal root component. Type $\mathrm{C}$ refers to a mesial located cervical part, while type AC refers to a central location, between the distal and mesial root components. This classification allows for the identification of separate and non separated radix entomolaris. According to the classification of De Moor et al. (2004), based on the curvature of the separate radix entomolaris variants in the bucco-lingual orientation, three types can be identified. Type I refers to a straight root/root canal, while type II refers to an initially curved entrance which continues as a straight root/root canal. Type III refers to an initial curve in the coronal third of the root canal and a second curve beginning in the middle and continuing to the apical third [1]-[3] [5]-[7] [10]-[12].

Guttapercha cone fit radiograph was taken from a more mesial angle using SLOB rule. The radiograph showed the radix entomolaris was separated from the distobuccal root. According to Carlsen and Alexandersen (1990), radix entomolaris in this case was classified as type A; and type III according to De Moor et al. (2004). Radix entomolaris, due to variations and complexities in its anatomy, may cause perforation or stripping, weakening of root, vertical root fracture, straightening of the root canal, ledge formation, loss of working length, root canal transportation, and instrument separation, particularly in the apical third of the root with a severe root inclination or canal curvature (as in a type III radix entomolaris) [2] [3] [7] [10]-[12]. Therefore, initial root canal exploration with small files (\#10 or less) and the creation of a glide path before preparation should be taken to avoid procedural errors. In this case, glide path was done using K-file to size \#15. The use of flexible nickel-titanium rotary files with crown down technique allows a more centered preparation shape [2]-[4] [7]-[12]. ProTaper Next with crown down technique was used in this case. In crown down technique, the coronal aspect of a root canal was prepared first before apical instrumentation commenced. Moreover, by first flaring the coronal two thirds of the canal, apical instruments are unimpeded through most of their length [13]. ProTaper Next is made with proven M-Wire nickel-titanium alloy for increased flexibility and resistance to cyclic fatigue compared to traditional nickel-titanium rotary instruments [14]. ProTaper Next also has an off-centered rectangular cross section design for greater strength, with unique asymmetric rotary motion that further enhances ProTaper canal shaping efficiency [15].

In this case, $2.5 \%$ sodium hypochlorite and $17 \%$ EDTA were used to irrigate root canals. Sodium hypochlorite is an effective antimicrobial agent, but it can only remove 
the organic components of the smear layer. EDTA can remove the inorganic components of the smear layer, so a combination of sodium hypochlorite and EDTA must be used to remove the smear layer effectively. Combination of these two irrigants in agitating movement used to clean the apical third of the root with a severe root inclination or canal curvature [16] [17].

To increase the rate of bacterial elimination in the root canal system and improve therapeutic efficacy, calcium hydroxide has been used as an antimicrobial intracanal dressing [18]. More canals mean more space for the bacteria to grow. It was a substance that inhibits microbial growth in canals. The antibacterial effect of calcium hydroxide was due to its alkaline $\mathrm{pH}$ from the hydroxyl ion. It was also dissolves necrotic tissue remnants and bacteria and their byproducts. Another therapeutic effect of calcium in calcium hydroxide was cellular stimulation, production, and mineralization [19].

Obturation was done with downpack-backfill technique. Downpack-backfill technique is a combined system of warm vertical compaction technique (downpack) to provide a better apical seal and thermoplastic injection technique (backfill) and to fill the coronal two thirds of the root canal. In order to seal the whole all root canal system, it is indispensable that the obturation should be three dimensional and hermetic; particularly in the last few millimeters of the apical area to make a good apical seal [20]. The epoxy resin sealer were used because of its good adhesion and sealing ability [21].

The final restoration for the tooth was full coverage onlay that covers part or the entire external surface of a tooth to recreate form and also fit within the tooth. This restoration was a reliable method for preventing fracture and provides a restoration with full coverage in order to protect the remaining tooth structure.

\section{Conclusion}

The radix entomolaris may be considered as a potential aetiologic factor for unsuccesful endodontic treatment. In this case, it was detected on the preoperative radiograph with the appearance of two outlines of the distal root contour. Root canals treatment on this case showed the lack of symptoms and normal radio graphical presentation on two months follow-up.

\section{References}

[1] de Pablo, Ó.V., Estevez, R., Sanchez, M.P., Heilborn, C. and Cohenca, N. (2010) Root Anatomy and Canal Configuration of the Permanent Mandibular First Molar: A Systematic Review. Journal of Endodontics, 36, 1919-1931.

[2] De Moor, R.J.G., Deroose, C.A.J.G. and Calberson, F.L.G. (2004) The Radix Entomolaris in Mandibular First Molars: An Endodontic Challenge. International Endodontic Journal, 37, 789-799. http://dx.doi.org/10.1111/j.1365-2591.2004.00870.x

[3] Calberson, F.L., De Moor, R.J. and Deroose, C.A. (2007) The Radix Entomolaris and Paramolaris: Clinical Approach in Endodontics. Journal of Endodontics, 33, 58-63. http://dx.doi.org/10.1016/j.joen.2006.05.007

[4] Gupta, S., Raisingani, D. and Yadav, R. (2011) The Radix Entomolaris and Paramolaris: A Case Report. Journal of International Oral Health, 3, 37-42. 
[5] Ballullaya, S.V., Vemuri, S. and Kumar, P.R. (2013) Variable Permanent Mandibular First Molar: Review of Literature. Journal of Conservative Dentistry, 16, 99-110. http://dx.doi.org/10.4103/0972-0707.108176

[6] Verma, S., Aggarwal, R., Aggarwal, R., Aggarwal, S., Bala, S. and Goel, M. (2013) Locating the Hidden Treasures in Endodontics: Radix Entomolaris: An Overview and a Case Report. Indian Journal of Dental Sciences, 5, 98-100.

[7] Dhoot, R., Zakirulla, M., Tejaswi, S.K.L., Nayak, R., Choudhury, G.K. and Manglekar, S.B. (2013) Radix Entomolaris: Clinical Approach in Endodontics. International Journal of Health Sciences and Research, 3, 151-156.

[8] Pawar, A.M., Kokate, S.R. and Hedge, V.R. (2013) Contemporary Approach in Successful Endodontic Intervention in Radix Entomolaris. World Journal of Dentistry, 4, 208-213. http://dx.doi.org/10.5005/jp-journals-10015-1233

[9] Alrahabi, M. (2014) Clinical Management of a Mandibular First Molar with Supernumerary Distal Root (Radix Entomolaris). Journal of Taibah University Medical Sciences, 9, 81-84. http://dx.doi.org/10.1016/j.jtumed.2013.11.001

[10] Pai, A.R.V., Jain, R. and Colaco, A.S. (2014) Detection and Endodontic Management of Radix Entomolaris: Report of Case Series. Saudi Endodontic Journal, 4, 77-82. http://dx.doi.org/10.4103/1658-5984.132723

[11] Irodi, S. and Farook, A.Z. (2011) Three Rooted Mandibular Molar: Radix Entomolaris and Paramolaris. International Journal of Dental Clinics, 3, 102-104.

[12] Nagaveni, N.B. and Umashankara, K.V. (2012) Radix Entomolaris and Paramolaris in Children: A Review of the Literature. Journal of Indian Society of Pedodontics and Preventive Dentistry, 30, 94-102. http://dx.doi.org/10.4103/0970-4388.99978

[13] Peters, O.A. and Peters, C.I. (2011) Cleaning and Shaping of the Root Canal System. In: Hargreaves, K.M., Cohen, S. and Berman, L.H., Eds., Pathways of the Pulp, 10 Edition, Mosby Elsevier, St. Louis, 283-348. http://dx.doi.org/10.1016/b978-0-323-06489-7.00009-6

[14] Pongione, G., Pompa, G., Milana, V., Di Carlo, S., Giansiracusa, A., Nicolini, E. and De Angelis, F. (2012) Flexibility and Resistance to Cyclic Fatigue of Endodontic Instruments Made with Different Nickel-Titanium Alloys: A Comparative Test. Annali di Stomatologia, 3, 119-122.

[15] Ruddle, C. Advanced Endodontics. http://www.endoruddle.com/tc2pdfs/show/137/PTNTechCard.pdf

[16] Kandaswamy, D. and Venkateshbabu, N. (2010) Root Canal Irrigants. Journal of Conservative Dentistry, 13, 256-264. http://dx.doi.org/10.4103/0972-0707.73378

[17] Basrani, B. and Haapasalo, M. (2012) Update on Endodontic Irrigating Solutions. Endodontic Topics, 27, 74-102. http://dx.doi.org/10.1111/etp.12031

[18] Estrel, C., Mamede Neto, I., Lopes, H.P., Estrela, C.R.A. and Pécora, J.D. (2002) Root Canal Filling with Calcium Hydroxide using Different Techniques. Brazilian Dental Journal, 13, 53-56.

[19] Lin, J. (2006) Intracanal Medicaments Revisited. New Zealand Endodontic Journal, 34, 4-15.

[20] Robberecht, L., Colard, T. and Claisse-Crinquette, A. 2012 () Qualitative Evaluation of Two Endodontic Obturation Techniques: Tapered Single-Cone Method versus Warm Vertical Condensation and Injection System: An In Vitro Study. Journal of Oral Science, 54, 99-104. http://dx.doi.org/10.2334/josnusd.54.99

[21] Johnson, W.T. and Kulild, J.C. (2011) Obturation of the Cleaned and Shaped Root Canal 
System. In: Hargreaves, K.M., Cohen, S. and Berman, L.H., Eds., Pathways of the Pulp, 10 Edition, Mosby Elsevier, St. Louis, 349-388.

http://dx.doi.org/10.1016/b978-0-323-06489-7.00010-2

Submit or recommend next manuscript to SCIRP and we will provide best service for you:

Accepting pre-submission inquiries through Email, Facebook, LinkedIn, Twitter, etc. A wide selection of journals (inclusive of 9 subjects, more than 200 journals)

Providing 24-hour high-quality service

User-friendly online submission system

Fair and swift peer-review system

Efficient typesetting and proofreading procedure

Display of the result of downloads and visits, as well as the number of cited articles

Maximum dissemination of your research work

Submit your manuscript at: http://papersubmission.scirp.org/

Or contact ojst@scirp.org 